\title{
A Review of the Erosion of Thermal Barrier Coatings
}

\author{
R. G Wellman and J. R. Nicholls
}

\author{
Cranfield University, Cranfield, Bedford, UK
}

\begin{abstract}
The application of thermal barrier coatings (TBCs) to components with internal cooling in the hot gas stream of gas turbine engines has facilitated a step increase in the turbine entry temperature and the associated increase in performance and efficiency of gas turbine engines. However, TBCs are susceptible to various life limiting issues associated with their operating environment including, erosion, corrosion, oxidation, sintering and foreign object damage.
\end{abstract}

This is a review paper that examines various degradation and erosion mechanisms of thermal barrier coatings, especially those produced by electron beam physical vapour deposition (EB PVD) . The results from a number of laboratory tests under various impact conditions are discussed before the different erosion and foreign object damage mechanisms are reviewed. The transitions between the various erosion mechanisms are discussed in terms of the $\mathrm{D} / \mathrm{d}$ ratio (contact area diameter / column diameter), a relatively new concept that relates the impact size to the erosion mechanism. The effects of aging, dopent additions and CMAS on the life of TBCs is examined. It is shown that while aging increases the erosion rate of EB PVD TBCs, aging of plasma sprayed TBCs in fact lowers the erosion rate. Finally modelling of EB PVD TBCs is briefly introduced.

Nomenclature:

7YSZ - 7wt\% Yttria partially Stabilised Zirconia

APS - Air Plasma Sprayed

AR - As received

BC - Bond Coat

CMAS - Calcium Magnesium Alumina Silicates

$\mathrm{d}$ - Column diameter

D - Contact area diameter

EB - Electron Beam

FOD - Foreign Object Damage

MCrAlY - An alloy containing chrome, aluminium and yttrium where M is typically Nickel and or Cobalt PS - Plasma Sprayed

PVD - Physical Vapour Deposition

SEM - Scanning electron microscope

$\mathrm{T} 1$ - sink temperature

$\mathrm{T} 2$ - operating temperature

TBC - Thermal Barrier Coatings

TET - Turbine Entry Temperature

TGO - Thermally Grown Oxide

YSZ - Yttria partially Stabilised Zirconia

$\varepsilon$ - Efficiency

$\gamma$ - gamma phase

$\gamma^{\prime}$ - gamma prime phase 


\section{INTRODUCTION}

Since the concept of thermal barrier coatings (TBCs), which can reduce the metal surface temperature of cooled turbine blades by up to $150^{\circ} \mathrm{C}$, was introduced in gas turbines $40 \mathrm{yrs}$ ago there has been a significant and steady increase in turbine entry temperature (TET). This drive towards a higher TET is a direct result of the drive towards more fuel efficient engines. The efficiency $(\varepsilon)$ of a heat engine is given by the following equation [1]:

$$
\varepsilon=\frac{T_{2}-T_{1}}{T_{2}} \quad \text { (Equation 1) }
$$

where, $T_{2}$ is the operating temperature and $T_{1}$ is the sink temperature.

Thus an increase in $\mathrm{T}_{2}$ (TET) results in an increase in efficiency of the engine. TBCs are essentially multilayered coating structures that consist of a bondcoat that is applied to the substrate, a thermally grown oxide (TGO) and a ceramic topcoat, typically an yttria stabilized zirconia. The bond coat can be applied by either thermal spraying or by diffusion methods. The TGO is formed between the bond coat and the ceramic top coat, during the production of the coatings as a result of the oxidation of the bondcoat and continues to grow throughout the life of the coating. Currently there are two basic production routes that are used for modern TBC systems; plasma spraying (PS) - in vacuum for the bond coat and air for the top coat or electron beam (EB) physical vapour deposition (PVD). These two systems result in very different microstructures and properties as illustrated in Figure 1.

Plasma sprayed TBCs in the form of $\mathrm{MgO}$ stabilized zirconia were first used in burner cans in 1963 [2] by Pratt and Whitney, however in the 1980's 7wt\% yttria stabilized zirconia emerged as the industry standard top coat [2]. By the late 1980s EB PVD techniques were being used to deposit the top coat onto rotating blades, which due to their columnar microstructure were more strain tolerant making them ideal for operating under high thermal cyclic conditions [2,3]. Currently both plasma sprayed and EB PVD TBCs are widely used on different components in modern gas turbine engines. Typically EB PVD TBCs are used on aerofoils in aero-engines, due to their higher strain tolerance in high temperature high cycle applications, while PS TBC are typically used for combustor cans in aero-engines and on turbine blades and combustor cans for land based gas turbines. The different components within a TBC system are:

A bondcoat system: Bondcoats for TBCs include the established MCrAlY series of environmental protection coatings, diffusion aluminides and most recently the gamma + gamma prime $\left(\gamma+\gamma^{\prime}\right)$ platinum diffused single crystal materials [22-25].

The thermally grown oxide (TGO): The mode and rate of growth of the thermally grown oxide is critical to the durability of the TBC system. Since the conception of TBC systems much work has been undertaken to understand how the alumina oxide grows, interacts, degrades and finally fails during high temperature service, specifically as measured by the thermal cyclic life [26-31]. The multi-material aspects of the TBC system complicate this understanding through diffusion, stress relaxation and chemical interactions between the component parts

An outer ceramic top coat - The most prevalent material is $\mathrm{ZrO}_{2}-(7-8) w t \% \mathrm{Y}_{2} \mathrm{O}_{3}$ (YSZ), although a number of alternative ceramics have also been considered. Newer materials having lower thermal conductivities include zirconia with multiple rare earth stabilizers [4-7] and pyrochlore phases, such as gadolinium zirconate [7]. Anecdotal evidence suggests that these alternative materials exhibit inferior erosion resistance and a greater susceptibility to delamination than the commercial standard 7YSZ $[8,9]$. Thus, the challenge in developing new oxide systems with enhanced overall performance is to understand the dichotomy between improved thermal resistance and the ceramics reduced durability [8]. The issues of erosion and foreign object damage performance will be addressed in this paper. 


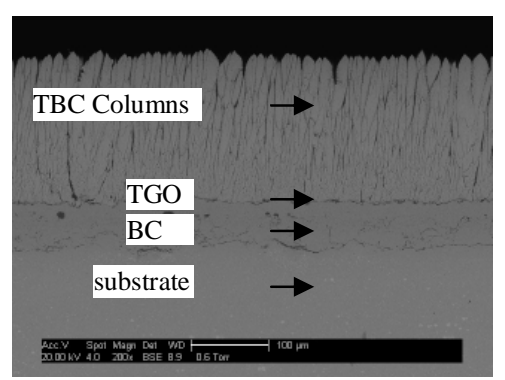

(a)

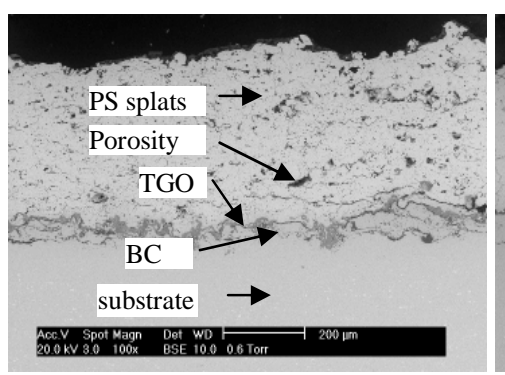

(b)

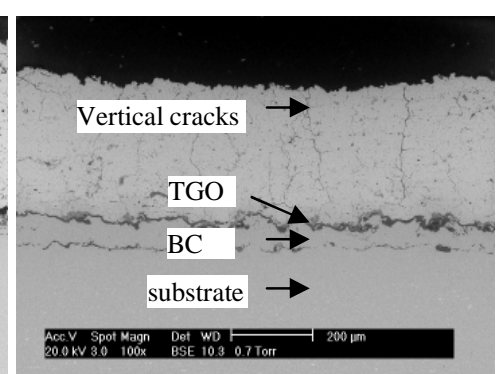

(c)

Figure 1: Scanning electron microscope (SEM) micrographs of various TBC microstructures, a) an EB PVD TBC, b) a PS TBC, c) a segmented (vertically cracked) TBC.

The SEM micrographs in Figure 1a-c show the various microstructural features of the different types of thermal barrier coatings. In Figure 1a one can see the typical columnar microstructure of the EB PVD ceramic top coat, it is this columnar structure that gives this type of TBC its strain tolerance. In Figure $1 \mathrm{~b}$ one can see the typical 'splat' morphology of a PS TBC with the associated porosity, while in Figure 1c the vertical cracks are clearly visible.

During the early years of TBC use in gas turbine engines oxidation of the bond coat was typically accepted as the primary cause of failure, and has thus been extensively researched, specifically issues associated with thermal cycling of the TBC [10-13]. Erosion of TBCs while acknowledged as a problem $[14,15]$ has until recently been considered a secondary problem, however with the use of EB PVD TBCs on turbine blades erosion has become more of an issue and has received more attention with numerous papers covering the topic of TBC erosion. Early work concentrated on the effect of variables like velocity, impact angle and erodent properties [16-19], while more recent work has examined erosion mechanisms [20-22] and the effects of aging and dopent additions [23].

However, as the ceramic top coat and the processing have developed the temperatures at which TBCs have operated has increased significantly resulting in oxidation issues with the bond coat and more recently, with the surface of the TBC reaching temperatures greater than $1240^{\circ} \mathrm{C}, \mathrm{CMAS}$ attack. CMAS, or calcium magnesium alumina silicates, is a low melting point flux which can form deposits on the surface of the TBC. When the surface temperature is greater than $1240^{\circ} \mathrm{C}$, the CMAS melting temperature [24], the CMAS will infiltrate the TBC resulting in extensive degradation of the columnar microstructure and 'locking' the tops of the columns together on cooling resulting in a loss of strain tolerance.

The schematic in Figure 2 illustrates the various degradation mechanisms that can occur to thermal barrier coatings during service in gas turbine engines. During laboratory testing most of these issues are investigated independently, whereas in reality a number of these mechanisms are normally occurring simultaneously. This paper briefly discusses various degradation mechanisms before briefly examining the interactions between sintering, aging, dopent addition and CMAS on the erosion rates of TBCs.

Initially perceived as being of secondary importance - when compared to bondcoat oxidation - for static parts, erosion and foreign object damage (FOD) become more significant for rotating hardware in advanced gas turbine engines. Particularly, the recent observations that the erosion resistance of many of the new lower thermal conductivity TBCs is worse than the commercial 7YSZ materials [9] and that during service the erosion resistance of EB-PVD TBC coated parts can degrade by up to a factor of $\mathrm{x} 4$ due to ceramic sintering $[20,23]$. 


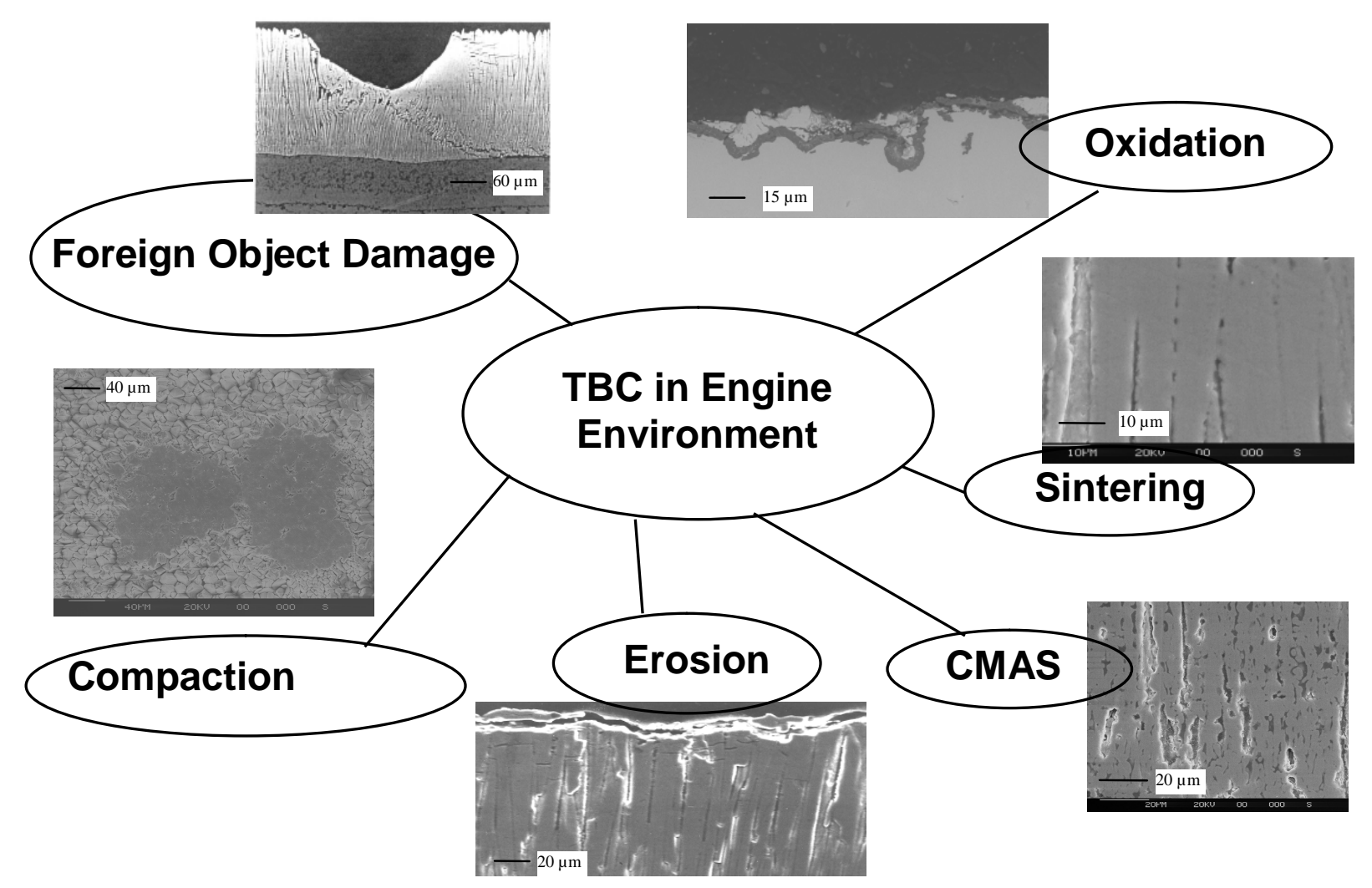

Figure 2: Schematic illustrating the types of damage that can occur to EB PVD TBCs in an engine environment.

For life-critical applications, erosion of the ceramic top coat is perceived as a potential problem, whether for aero- [16,25-29] or industrial applications [25,30]. Thermal barrier coatings are more susceptible to erosion than fully dense ceramics [31] because the coating microstructures contain many crack-like features.

\section{EXPERIMENTAL STUDIES ON THE EROSION OF THERMAL BARRIER COATINGS}

Studies into the erosion performance of thermal barrier coatings are somewhat limited in the published literature, with the majority of studies using either the Cincinatti wind tunnel rig, the Cranfield gas gun facility, or industrial burner rig facilities. The capabilities of the two laboratory test facilities were compared in a previous EPRI research workshop into corrosion in advanced power plants [32].

Experimental studies are roughly evenly split between studies of plasma sprayed systems [14,16,17,19,20,31,33-37] and EB-PVD systems [16,18,19,26,30,33,38], although data on the latter, to a significant degree, have only recently become available. Both laboratories (Cincinnati and Cranfield) have the ability to test at room temperature and elevated temperatures. Tests up to $815^{\circ} \mathrm{C}$ and $910^{\circ} \mathrm{C}$ have been undertaken in these test facilities respectively and the experiments undertaken in both facilities when testing coatings to the same manufacturing specification, give similar results $[17,31,35]$. The difference between the two approaches is that Cincinatti use a combustion based system, burning fossil fuels, to produce the hot gas stream; while Cranfield uses an electrically heated, high velocity gas gun [32]. 
Comparing results from both of these laboratories, and incorporating the limited experimental data from other laboratories, permits a data set for the erosion of APS (air plasma sprayed) TBCs over the temperature range room temperature $-1600^{\circ} \mathrm{C}$ and $\mathrm{EB}-\mathrm{PVD}$ coatings over the temperature range RT$910^{\circ} \mathrm{C}$ to be established for particle velocities up to circa $300 \mathrm{~ms}^{-1}$. Recently limited data on the erosion of segmented, plasma sprayed TBCs is also available from recent tests [45].

Trends from this dataset, together with current understanding of the mechanisms of failure under erosion and FOD are discussed in this paper.

Firstly, Figure 3 presents a comparison of the erosion performance of an air plasma sprayed (APS) TBC, with a lamellar microstructure resulting from the deposition of pancake like splat particles, to an EB-PVD $\mathrm{TBC}$ with the classic columnar microstructure. Tests on bulk zirconia are included as a reference. Bulk $\mathrm{ZrO}_{2}-8 \mathrm{wt} \% \mathrm{Y}_{2} \mathrm{O}_{3}$ when eroded with $100 \mu \mathrm{m}$ alumina particles gave erosion rates of $3.6 \pm 0.1 \mathrm{~g} / \mathrm{kg}$ at room temperature (particle velocity was $140 \mathrm{~m} / \mathrm{s}$ ) and $12.5 \pm 2.9 \mathrm{~g} / \mathrm{kg}$ at $910^{\circ} \mathrm{C}$ (particle velocity was $230 \mathrm{~m} / \mathrm{s}$ ) [17,39]. Also included in Figure 3 are the more recent erosion studies undertaken on a segmented plasma sprayed microstructure (see Figure 1c).

It can be seen from Figure 3 that at room temperature $\left(20^{\circ} \mathrm{C}\right)$ and $910^{\circ} \mathrm{C}$, the columnar EB-PVD microstructure is more erosion resistant than the splat-like APS microstructure by a factor of approximately x10, under normal $\left(90^{\circ}\right)$ impact conditions. Erosion rates were respectively $20 \mathrm{~g} / \mathrm{kg}\left(20^{\circ} \mathrm{C}\right.$, $140 \mathrm{~m} / \mathrm{s})$ and $28.5 \mathrm{~g} / \mathrm{kg}\left(910^{\circ} \mathrm{C}, 230 \mathrm{~m} / \mathrm{s}\right)$ for the EB-PVD columnar microstructure compared to $210 \mathrm{~g} / \mathrm{kg}$ $\left(20^{\circ} \mathrm{C}, 140 \mathrm{~m} / \mathrm{s}\right)$ and $322 \mathrm{~g} / \mathrm{kg}\left(910^{\circ} \mathrm{C}, 230 \mathrm{~m} / \mathrm{s}\right)$, for the splat-like APS microstructure. The vertically microcracked plasma sprayed TBC by comparison - although only tested at room temperature - exhibited erosion rates much closer to that expected for EB-PVD ceramic than APS ceramic, namely $24.4 \mathrm{~g} / \mathrm{kg}$ $\left(20^{\circ} \mathrm{C}, 140 \mathrm{~m} / \mathrm{s}\right)$.

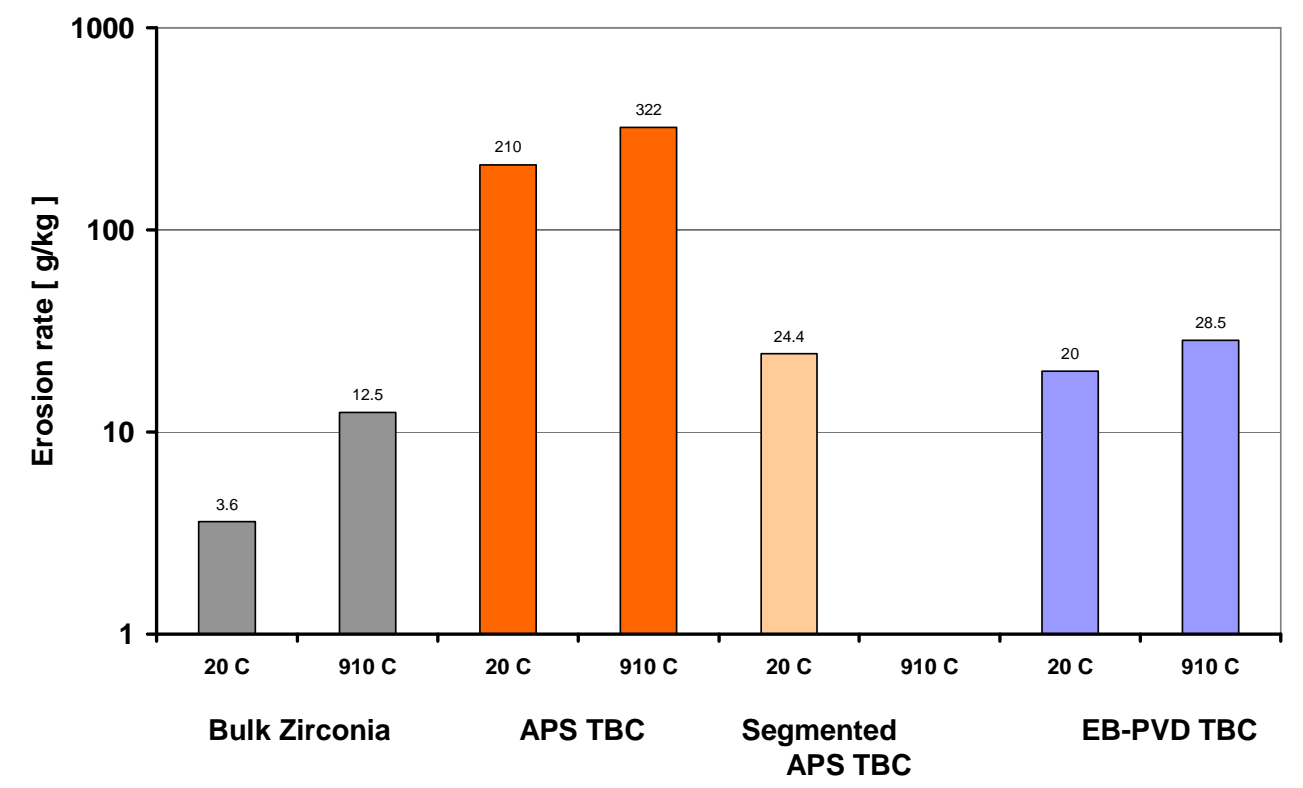

Figure 3: Comparison of the erosion performance of air plasma sprayed, EB-PVD and segmented plasma sprayed coatings at $\mathrm{RT}$ and $910^{\circ} \mathrm{C}$. Data for bulk $\mathrm{ZrO}_{2}-7 \mathrm{wt} \% \mathrm{Y}_{2} \mathrm{O}_{3}$ ceramic is included as a reference

All coating morphologies are significantly less erosion resistant than the bulk ceramic (the EB-PVD ceramic erodes at $\mathrm{x} 2$ to $\mathrm{x} 5$ the rate of bulk zirconia, depending on test temperature), confirming the premise that the crack-like features inherent in the design of successful thermal barriers must compromise 
the erosion performance. The ability of the columnar boundaries in the EB-PVD ceramic microstructure (and the vertical microcracks in the segmented APS TBC) to limit crack propagation is thought to account for its improved erosion resistance over the conventional air plasma sprayed microstructure.

Recent room temperature erosion studies undertaken at Cranfield under the HIPERCOAT programme on gadolinia doped $(2 \mathrm{~mole} \%)$, zirconia- 4 mole $\%(7 \mathrm{wt} \%)$ yttria confirmed the anecdotal evidence that rare earth doped EB-PVD TBCs erode at a higher rate (less erosion resistant) than the industrial standard $\mathrm{ZrO}_{2-}$ $7 \mathrm{wt} \%$ (4 mole\%) $\mathrm{Y}_{2} \mathrm{O}_{3}$ material. The measured erosion rate using $90-125 \mu \mathrm{m}$ alumina, at $90^{\circ}$ impact with a particle velocity calculated to be $100-110 \mathrm{~m} / \mathrm{s}$ was $29-34 \mathrm{~g} / \mathrm{kg}$, 2-3x that of the $\mathrm{ZrO}_{2}-7 \mathrm{wt} \% \mathrm{Y}_{2} \mathrm{O}_{3}$ material, at $11-13 \mathrm{~g} / \mathrm{kg}$ [40]. Clearly this dichotomy between improved thermal resistance and reduced damage tolerance must be addressed so that advanced ceramic systems with balanced properties and improved overall performance can be developed.

\subsection{Erosion Performance of Commercial EB-PVD Thermal Barrier Coatings Deposited onto Aerofoil Components}

At Cranfield repeat EB-PVD TBCs, of commercial manufacture, have been tested using $100 \mu \mathrm{m}$ alumina at $230 \mathrm{~ms}^{-1}$ and $910^{\circ} \mathrm{C}[31]$ or $140 \mathrm{~ms}^{-1}$ at room temperature [17,39]. The aim of this series of tests was to evaluate the repeatability of erosion behaviour from sample to sample (using $25 \mathrm{~mm} \times 25 \mathrm{~mm}$ test pieces) and by location around a coated blade (samples were cut from the suction surfaces, pressure surface and from the leading edge). The repeatability of the test pieces reflects the reproducibility of the coating process from one run to another, while the repeatability of samples taken from a blade reflects the reproducibility of manufacture around a blade profile.

Measured erosion rates on test pieces (TBC thickness $360 \mu \mathrm{m}$ ), when tested at $90^{\circ}$ impact and $910^{\circ} \mathrm{C}$ using $100 \mu \mathrm{m}$ alumina at a velocity of $230 \mathrm{~m} / \mathrm{s}$, varied between 14.0 and $28.5 \mathrm{~g} / \mathrm{kg}$ with a mean of $19.8 \mathrm{~g} / \mathrm{kg}$. The data, shown as solid diamond symbols in Figure 4, was found to fit a classical Weibull model (depicted in the following equation), when plotted as erosion resistance (1/erosion rate) where $F_{w}$ is the Weibull probability, $\mathrm{E}$ is the erosion rate, $\mathrm{E}_{\mathrm{o}}$ is a minimum erosion rate under these test conditions and $\beta, \eta$ are constants.

This is to be expected for fracture behaviour controlled by the size of inherent defects. The Weibull model was of the form:

$$
F_{w}=1-\exp \left\{-\left(\frac{1 / E-1 / E_{o}}{\eta}\right)^{\beta}\right\}
$$

Transforming Equation 2 by taking double logarithms one obtains:

$$
\ln \left(-\ln \left(1-F_{w}\right)\right)=\beta \ln \left(\frac{1}{E}-\frac{1}{E_{o}}\right)-\beta \ln \eta \quad(\text { Equation 3) }
$$


Thus a plot of $\ln \left(-\ln \left(1-F_{w}\right)\right)$ vs $\ln (1 / E)$ allows the Weibull slope $\beta$ and the characteristic erosion rate $\eta$ to be evaluated. Where the Weibull modulus $\beta$ takes a value of 3.6 for batch to batch variations in EBPVD TBC manufacture. The characteristic erosion resistance $(\eta)$ for this data set is $0.060 \mathrm{~kg} / \mathrm{g}$ (corresponding to a characteristic erosion rate of $16.8 \mathrm{~g} / \mathrm{kg}$ ).

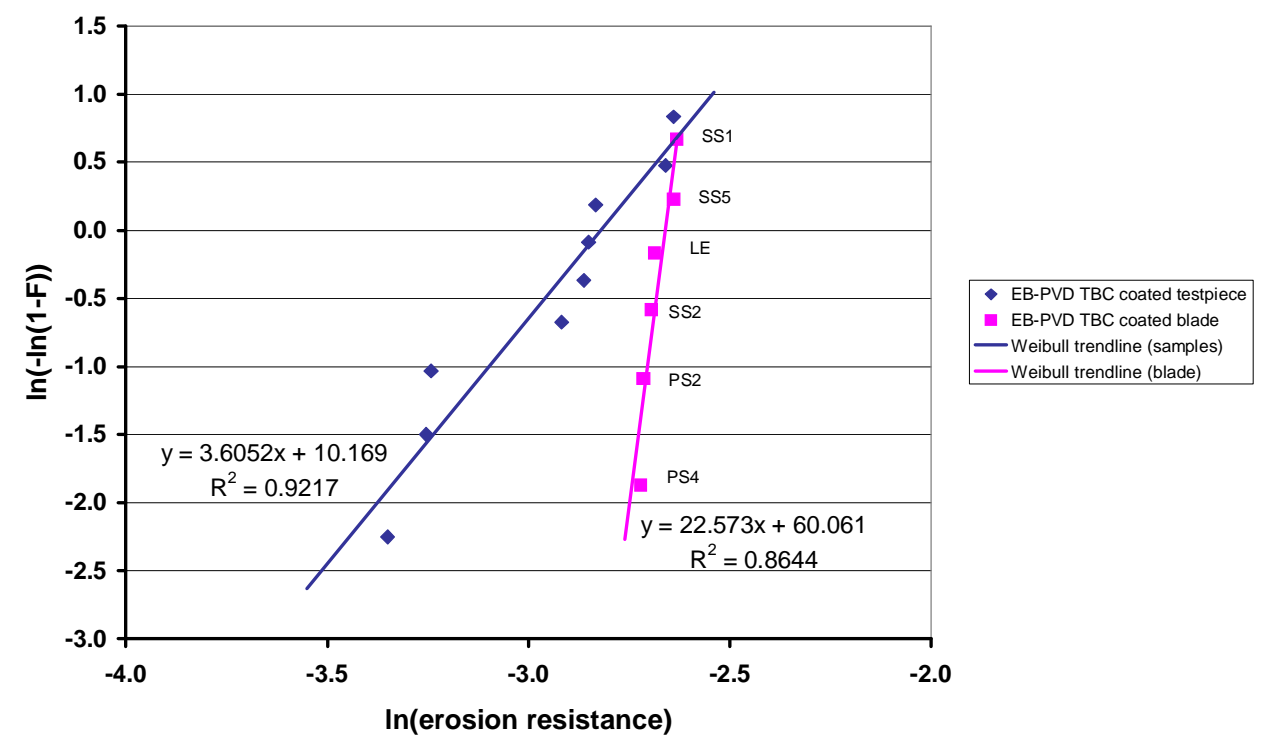

Figure 4: Weibull analysis of the repeatability of erosion data for EB-PVD thermal barrier coatings tested at $9^{\circ} \mathrm{C}$ [Included in this figure is data taken from Figure 5 on a blade sample, which represents the most likely within batch variation: Note: the $R^{2}$ values quoted on the figure are a measure of the 'goodness of fit'; an $\mathbf{R}^{2}$ value of 1.0 is a perfect fit to the data].

TBC coated blade samples, courtesy of CUK Ltd, were provided as a through blade section cut from an industrial turbine blade, coated with $\mathrm{ZrO}_{2}-8 \mathrm{wt} \% \mathrm{Y}_{2} \mathrm{O}_{3}$, EB-PVD ceramic. Each segment tested was $25 \mathrm{~mm}$ $\mathrm{x} 25 \mathrm{~mm}$ area approximately with 10 segments taken around the blade profile (label SS1 to SS5 along the suction surface, LE leading edge and PS1 to PS4 along the pressure surface). Six of these samples have been erosion tested at $90^{\circ}$ impact at room temperature, using $100 \mu \mathrm{m}$ alumina at a velocity of $140 \mathrm{~m} / \mathrm{s}$. Figure 5 plots the result of this study, effectively mapping the erosion rate of the EB-PVD TBC around the blade profile. Erosion rates varied around the blade profile, from $13.9 \mathrm{~g} / \mathrm{kg}$ on the pressure surface (PS4) to $14.8 \mathrm{~g} / \mathrm{kg}$ on the leading edge (LE) and a maximum of $15.2 \mathrm{~g} / \mathrm{kg}$ on the suction surface (SS1). This trend maps out the degree of constraint around the blade, for on the suction surface the coating grows into a more open space (convex surface), while on the pressure surface the space is constrained (a concave surface). These growth constraints will modify the EB-PVD column size and the extent of intra-column porosity, thus influencing the erosion rate.

Whilst discussing constraints introduced by blade geometries another factor that must be taken into account is the likelihood of producing inclined column microstructures during the manufacture of EBPVD TBC coated turbine parts. Areas prone to these non-ideal microstructures are the shrouds and platforms of the high pressure turbine blades and the deposition into the intra-vane spacing for nozzleguide vane pairs. Inclined columns on platforms and shrouds can be partially alleviated by applying a butterfly action to the blade manipulators during TBC deposition. However, such remedial actions are not possible when considering the constraints offered by nozzle guide vane pairs. Here the column inclination 
is defined by the incident angle of the vapour flux and the available aperture between the pair of nozzle guide vanes.

Good erosion resistance of EB-PVD thermal barrier coatings requires that the columnar microstructure is vertically aligned. Any off axis symmetry modifies the mode of column fracture and this has a significant effect on the erosion rate. Figure 6 illustrates the increase in erosion damage that can occur when the TBC growth direction is inclined. On impact, fracture may occur throughout the coating (rather than in the near surface region as discussed in the next section for a vertically aligned EB-PVD TBC microstructure) with some fracture at mid-column length and others near to the bond coat surface. This behaviour is believed to result from bending of the columns during impact, such that the largest defect in the column surface causes fracture.

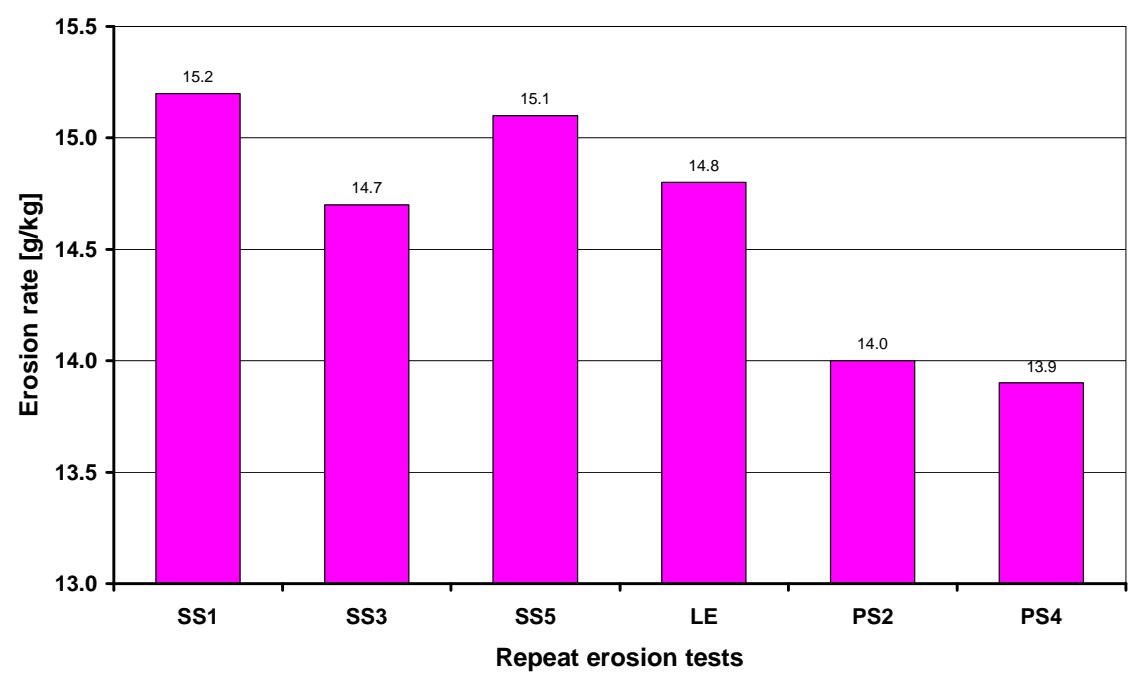

Figure 5: Variation in erosion rate of a commercial EB-PVD TBC around a blade profile.

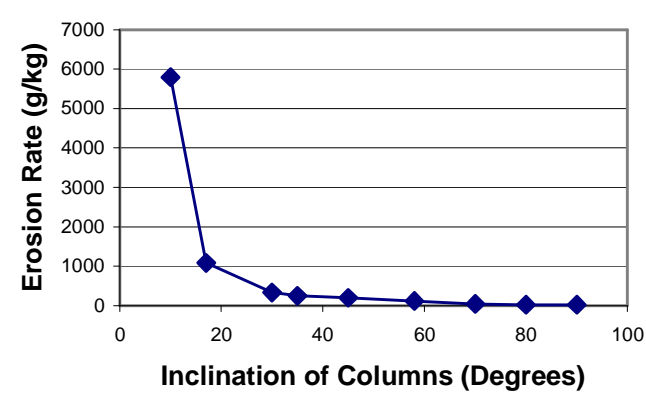

a) Column inclination $7^{\circ}$ to $90^{\circ}$

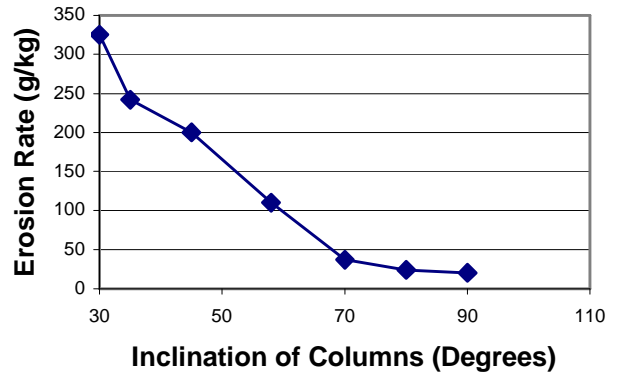

b) Enlargement of region $30^{\circ}$ to $90^{\circ}$

Figure 6: Influence of column inclination on the erosion rate of EB-PVD TBCs [21].

Clearly, the TBC microstructure, developed as part of the manufacturing process can have a major effect on erosion behaviour. This effect of column inclination would be significant when coating such components as nozzle guide vanes, which are often designed with multiple aerofoil parts. At shallow 
angles of inclination $<7.5^{\circ}$, erosion rates in excess of $6,000 \mathrm{~g} / \mathrm{kg}$ are observed (see Figure 6). In fact, the EB-PVD TBC performs worse than an APS TBC when the columns are inclined at angles below $50^{\circ}$. For acceptable performance it is recommended that off axis inclination be kept less than $15^{\circ}$ (i.e. inclinations between $75-90^{\circ}$ ). This would give a doubling of the erosion rate.

\subsection{OBSERVED DAMAGE MECHANISMS IN THE EROSION AND FOREIGN OBJECT DAMAGE OF EB-PVD TBCS}

It has been demonstrated in the previous section that EB-PVD TBCs are inherently more erosion resistant than their air plasma sprayed counterpart. Factors between $\mathrm{x} 7$ and $\mathrm{x} 10$ have been reported depending on the exact test conditions and ceramic microstructure developed in coating manufacture. This section discusses the material removal mechanisms and the role of microstructure.

The difference in erosion behaviour is associated with the differing modes of failure for an air plasma sprayed (APS) and EB-PVD coatings. The APS coating fails by the propagation of cracks along splat boundaries and through the microcrack network that are an inherent part of the microstructure and which provide some degree of strain tolerance [31]. In contrast, the EB-PVD coating when impacted by particles of $100 \mu \mathrm{m}$ or less forms parallel, near surface cracks within the columns [17,35,36]. Cracks stop at column boundaries, see Figure 7, and a number of neighbouring columns need to fracture before material is lost.

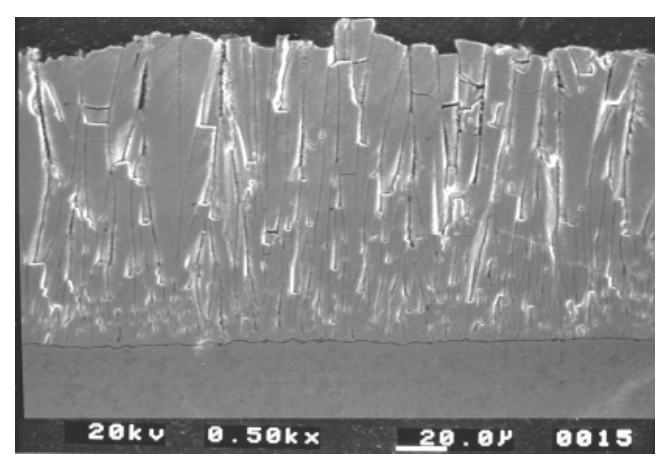

(a) Room Temperature

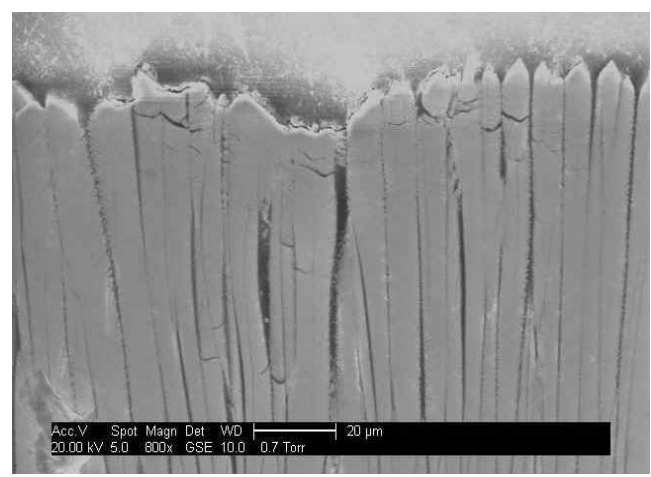

(b) $800^{\circ} \mathrm{C}$

Figure 7: SEM cross sections of eroded samples of EB PVD TBCs showing near surface cracking, a) at room temperature and b) at $800^{\circ} \mathrm{C}$

The mechanism of foreign object damage (FOD) is more complicated and involves gross plastic damage and shear bands within the TBC $[9,26,35,39]$ often leading to cracks down to the metal oxide interface and thus large scale ceramic removal (see Figure 10a)-c) later in this paper).

In the following sections, the different erosion and FOD mechanisms will be discussed and defined according to the observed damage for the different impact conditions starting with low energy impacts.

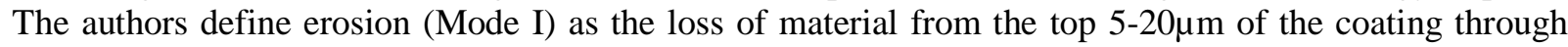
repeated impact by small particles causing near surface cracking in individual columns. FOD (Mode III) involves gross plastic damage, the bending of columns and ultimately the propagation of shear bands down to the ceramic bond coat interface. Between these two modes exists a transition mode which has been termed compaction damage (Mode II). 
One thing that has become clear during the study of the erosion of EB PVD TBC is that the particle size and velocity appear to be intrinsically linked when trying to ascertain the erosion regime of the TBC. Previous work by Wellman and Nicholls [37] on erosion of EB PVD TBCs resulted in the development of an erosion map, shown in Figure 8, depicting the different erosion regimes that will be discussed in the following sections. However, subsequent work has shown that the ratio between the contact footprint and the column diameter is perhaps a better way to ascertain the erosion mechanism and this will be discussed in Section 3.4.

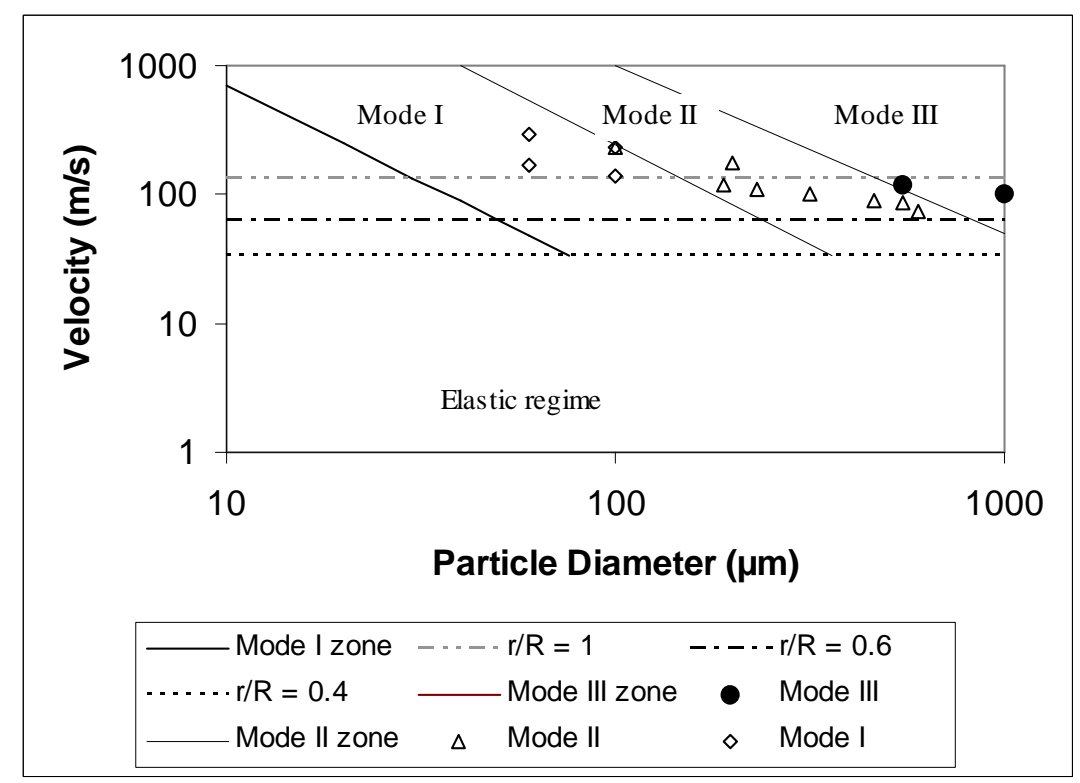

Figure 8: Erosion map for EB PVD TBCs showing relationship between particle velocity, size and erosion regime [37].

\subsection{Mode I - Erosion (Near surface cracking/lateral cracking)}

Erosion is the standard term used by most authors in the literature to describe the progressive loss of material from the surface of an EB PVD TBC while still maintaining the integrity of the columnar microstructure. This occurs under small particle impact conditions where the near surface region, the top $20 \mu \mathrm{m}$, of the individual columns are cracked due to impact. Material is lost when a number of neighbouring columns have been impacted and cracked. The cracks are observed to initiate at the elastic/plastic interface that occurs under the impacting particles [20], this type of damage is illustrated in Figure 7.

The relevance of room temperature erosion testing has been questioned as to whether it is representative of high temperature erosion. As far as can be seen from Figure $7 \mathrm{a}$ and $7 \mathrm{~b}$ the same mechanism of near surface cracking occurs at both room and high temperatures. Although, it can be argued that the degree of plastic deformation that can be accommodated by the ceramic at elevated temperatures is greater than at room temperature. However, analysis of samples eroded at both room temperature and high temperature showed that there was no difference in the observed depth at which the near surface cracking occurred during Mode I erosion of the samples.

Erosion rates are highly dependent on a number of material properties which include Young's Modulus, Hardness and Fracture Toughness, all of which are affected by temperature. Thus, it can be argued that 
although the erosion mechanism at room temperature and high temperature is nominally similar the erosion rates could well be different.

\subsection{Mode II - Compaction Damage}

This is a relatively new observation and is essentially a transition mechanism that occurs between erosion and FOD. It involves the compaction of the columns without the cracking that occurs during erosion or the gross deformation of the columns that occurs during FOD. This type of damage has been observed under both room temperature and high temperature impact conditions, and is illustrated in Figure 9. Figure 9, a room temperature impact, illustrates the ability of EB PVD TBCs to deform plastically, even at room temperature. Note however, that this type of plastic deformation, as in Mode I erosion, is most likely in the form of the densification of the near surface individual columns. Penetration depths are expected to be greater than under Mode I erosion with the higher impact energies involved in Mode II compaction.

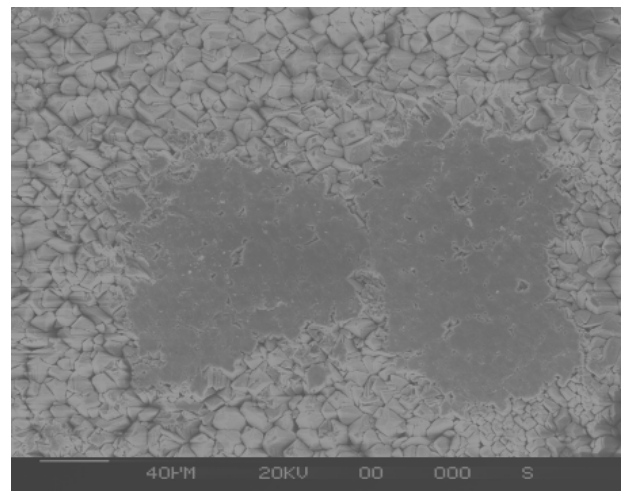

(a)

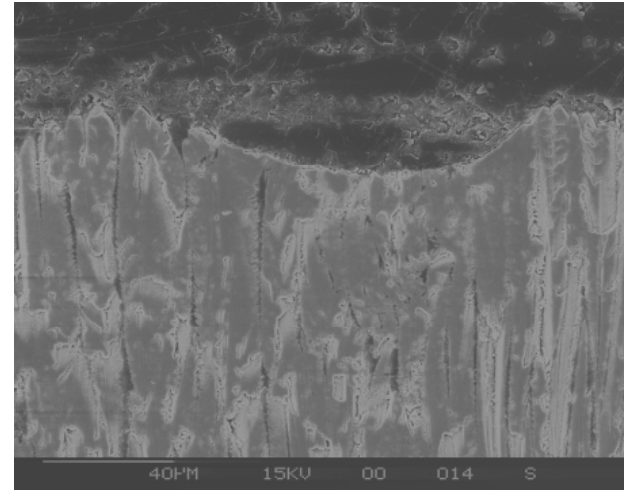

(b)

Figure 9: SEM micrographs of single impact Mode II compaction damage showing compaction of the coating, note the absence of cracking, a) top view, b) cross section. $[200 \mu \mathrm{m}$ particle impact, at $170 \mathrm{~m} / \mathrm{s}$ at room temperature].

Thus, in this intermediate/transition damage mechanism there is compaction of the EB PVD TBC columns, but neither the near surface cracking of Mode I nor the gross plastic deformation, kinking and cracking of Mode III is observed. This compaction damage is attributed to the high porosity levels in the columns, which are never $100 \%$ dense, often containing up to $15 \%$ of nano-sized porosity together with intra-column pores. A similar type of compaction occurs during Mode I, here the damage is limited to one or two neighbouring columns, with any lateral cracks believed also to initiate from the elastic/plastic interface. However, when the impact is spread over a significant number of columns, as is Mode II compaction damage, cracks do not initiate at this interface thus the transient loads on each column must be lower, below the fracture stress of the individual columns. This type of damage is observed for larger particles traveling at intermediate velocities and is thought to be due to a lower rate of energy input by the decelerating particle. This mechanism is still under investigation but it is evident from the initial single impact studies that the Mode II damage mechanism is different from the other two and that cracking does not occur under single impacts. Multiple impacts studies are underway to determine the exact mechanism that is operating under Mode II conditions, which may well be a form of impact fatigue damage.

\subsection{Mode III - Foreign Object Damage (FOD)}

FOD is caused by large particles travelling at low velocities or smaller particles at higher velocities and is 
characterised by significant deformation of the coating which can penetrate to the substrate and is accompanied by gross plasticity, deformation of the columns, shear bands and extensive cracking of the TBC ceramic [26],[9,17,35,41,42] as illustrated in Figure 10. Clearly, the extent of gross plasticity observed varies with the component temperature when impacted, being greatest at $1200^{\circ} \mathrm{C}$ and less prevalent at room temperature.

Further, recent studies have shown that, in fact, there are a number of distinct types of FOD. The SEM micrograph in Figure 11 illustrates an additional form of FOD damage - termed type 2 FOD - where significant column buckling is observed. This mode was observed in high velocity, gas gun FOD tests at Cranfield and demonstrates that EB PVD TBCs can deform plastically at elevated temperatures, in this case $800^{\circ} \mathrm{C}[21]$.

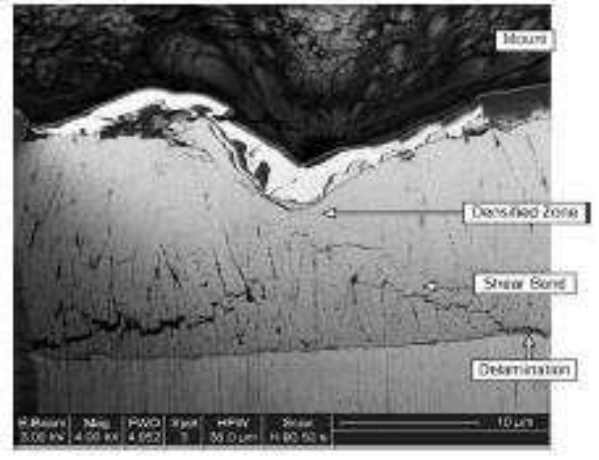

(a) $1200^{\circ} \mathrm{C}$

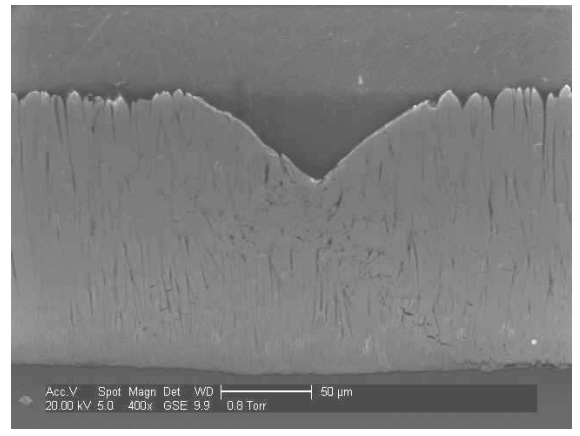

(c) $800^{\circ} \mathrm{C}$

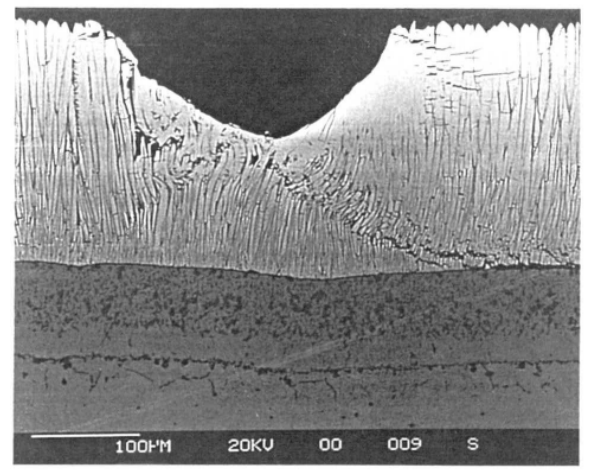

(b) $900^{\circ} \mathrm{C}$

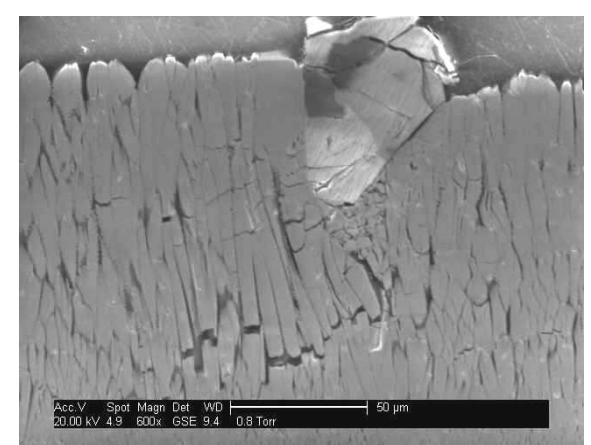

(d) Room temperature.

Figure 10: SEM micrographs illustrating the effect of FOD in an EB PVD TBC, a) damage at $1200^{\circ} \mathrm{C}$ [21,55], b) damage at $900^{\circ} \mathrm{C}[1 \mathrm{~mm}$ spherical alumina particle at an estimate $100 \mathrm{~m} / \mathrm{s}][26]$ c) $800^{\circ} \mathrm{C}$ [21] d) damage at room temperature $[0.5 \mathrm{~mm}$ angular alumina particle at an estimated $100 \mathrm{~m} / \mathrm{s}][21]$.

From these studies it appears that an additional type of foreign object damage can occur that involves significant buckling of the columns and plastic deformation without noticeable cracking. It is expected that subsequent impacts would increase the degree of buckling in the columns until cracking initiated and material was lost. FOD Type 1 is the standard accepted mechanism of gross plastic deformation of the coating with the associated densification bending and cracking of the columns as shown in Figure 10 a-c. While Type 2 FOD is a relatively new observed damage mechanism and as illustrated in Figure 11 involves gross plastic deformation of the TBC columns. These two mechanisms are not mutually exclusive and are discussed in the following sections. 


\subsection{1) Type 1 FOD}

Type 1 FOD may give rise to either of two damage morphologies. These morphologies result from essentially the same mechanism, differing only in the relative degree of cracking and plastic deformation that occurs, which is a direct result of the temperature of impact. As can be seen in Figure $10 \mathrm{a}-\mathrm{c}\left(1200^{\circ} \mathrm{C}\right.$, $900^{\circ} \mathrm{C}$ and $800^{\circ} \mathrm{C}$ ) Type $1 \mathrm{a}$ FOD exhibits a significantly greater degree of plastic deformation under the impact. Gross plastic deformation of the coating is in the form of compaction damage immediately below the impact with associated bending and cracking of the columns to form lateral shear bands propagating down to the ceramic/substrate interface. Type 1b FOD (room temperature) exhibits noticeably less gross plasticity (Figure 10d) instead there is a significant amount of cracking observed in the columns of the sample due to the more brittle nature of the ceramic columns at room temperature.

It is under conditions of FOD that the effect of temperature becomes most noticeable in that the mode of damage is directly affected by the temperature at which the impact occurs. After room temperature impact the columns are still visible as discreet features, whereas as the temperature increases, impact conditions result in the coating densifing as a whole. In other words the impact has caused adjacent columns to compact together so that they are no longer discreet columns.

\subsubsection{Type 2 FOD}

This mode of damage has only recently been observed in high temperature laboratory tests [21] and demonstrates the ability of EB PVD TBCs to deform plastically without densification occurring. As can be seen from Figure 11 the impacting particle has caused a number of columns in the coating to buckle with virtually no cracking occurring. From these experiments [21] this mode of deformation can be expected to occur at temperatures in excess of $800^{\circ} \mathrm{C}$ (being the temperature at which these tests were conducted) and possibly lower temperatures as well, provided the ceramic material exhibits sufficient plasticity. It is not expected that this damage mechanism will operate at room temperature.

Both Type 1 and Type 2 FOD were found to occur in the same sample and are thus not mutually exclusive mechanisms. Which mode of damage occurs can be assumed to depend on the local impact conditions, and the constraint between neighbouring TBC columns.

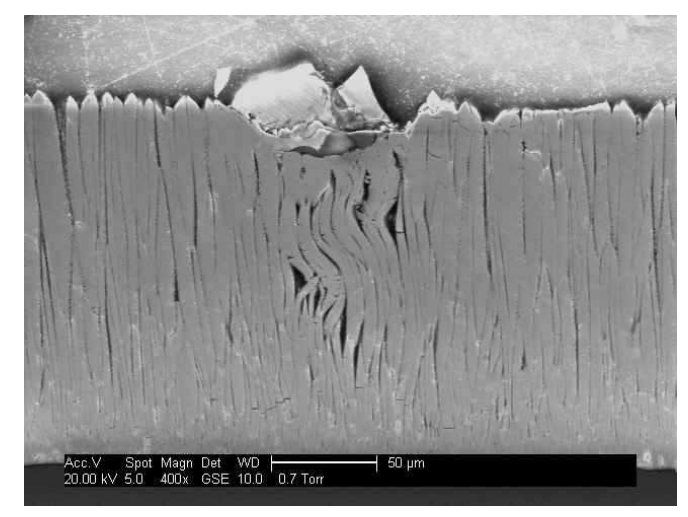

Figure 11: SEM micrograph illustrating type 2 FOD in EB PVD TBCs impacted at $800^{\circ} \mathrm{C}$ [21]. 


\subsection{The Dimensionless Erosion Ratio D/d}

These different erosion mechanisms can also be described in terms of the ratio between the contact diameter of the impacting particle and the column diameter. This is a similar principle to the measured decrease in TBC hardness with increasing load [43], which relates to the number of columns with which the indenter interacts as illustrated in Figure 12. This effect is due to the fact that at low loads the indenter is interacting with only one column and hence is measuring the hardness of a single column, however as the load increases the number of columns with which the indenter interacts increases resulting in greater system compliance and hence a lower measured hardness. As the load is increased the point is reached where the system compliance is no longer increasing and the hardness of the coating is being measured.

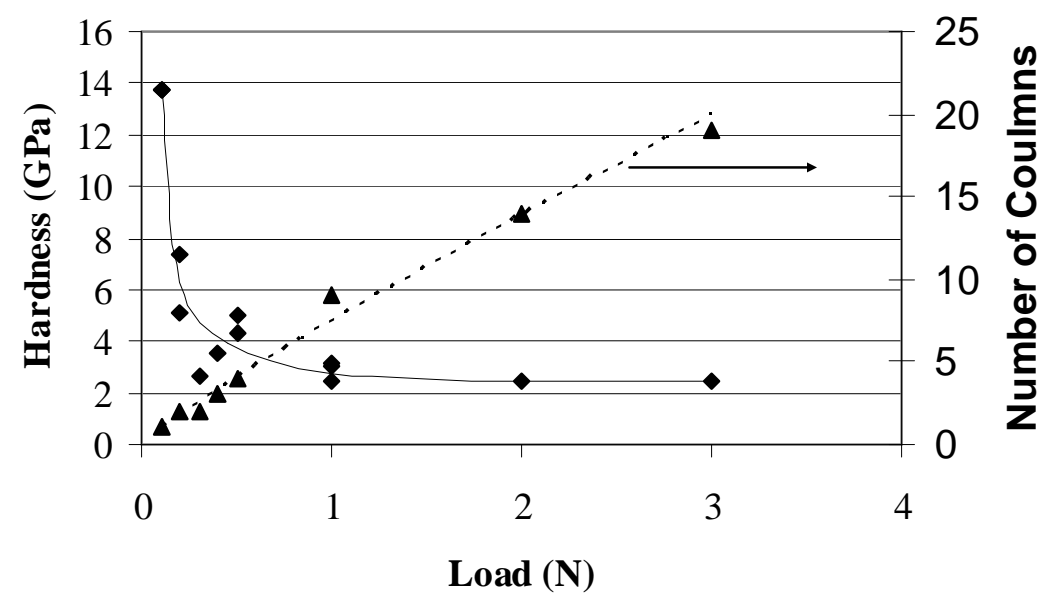

Figure 12: Effect of increasing load on the measured hardness of EBPVD TBCs.

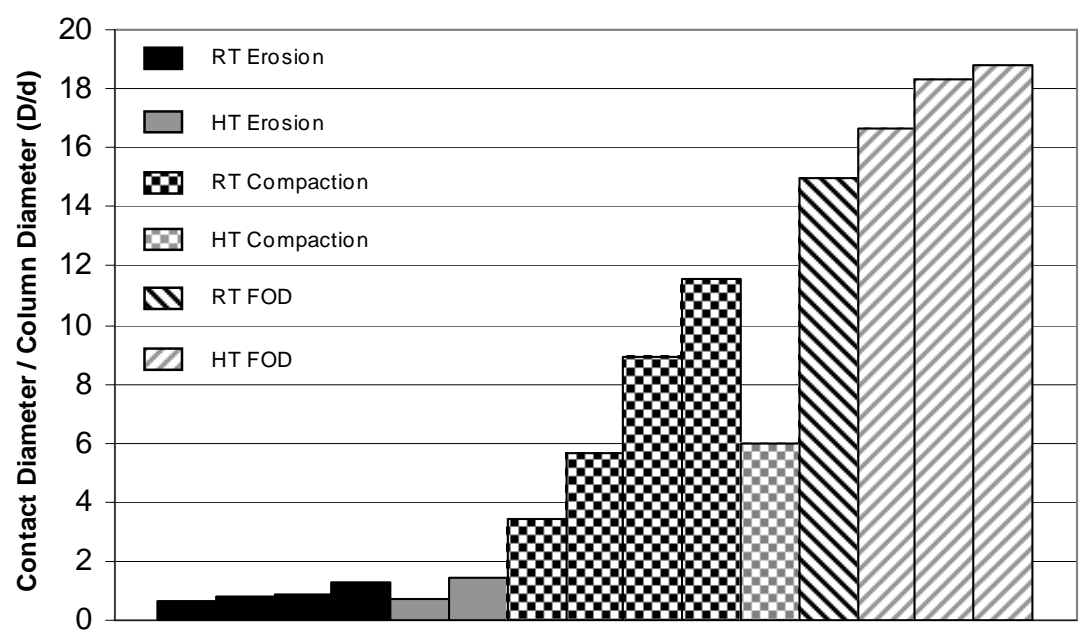

Figure 13: Graph of measured D/d ratios for different impact conditions. 
This observation initially led to the concept of the $\mathbf{D} / \mathbf{d}$ ratio, where $\mathbf{D}$ is the contact footprint diameter and d is the column diameter. This dimensionless ratio takes into account a number of otherwise difficult to resolve variables, including coating and particle mechanical properties, particle size and particle velocity. The graph in Figure 13 shows that the $\mathbf{D} / \mathbf{d}$ ratio allows one to clearly determine the damage mechanism that is operating under particle impact conditions. Further work needs to be conducted to couple the D/d ratio with the strain rate in order to generate a new type of erosion map. As can be seen from the graph in Figure 13 a D/d ratio of less than 2 indicates an erosion mechanism, while a ratio of 2-12 indicates a compaction mechanism and greater than 12 a foreign object damage mechanism. For the measured results so far it appears as though this ratio is independent of temperature. At this stage it is not possible to relate erosion rate directly to the $\mathbf{D} / \mathbf{d}$ ratio, since during FOD if the damage does not reach the ceramic bond coat interface the erosion rate will be significantly lower than for cases where it does. This relationship has not yet been studied for other systems although it could prove a useful tool for examining the erosion performance of dual phase materials, for example WC-Co cermets and metal matrix composites.

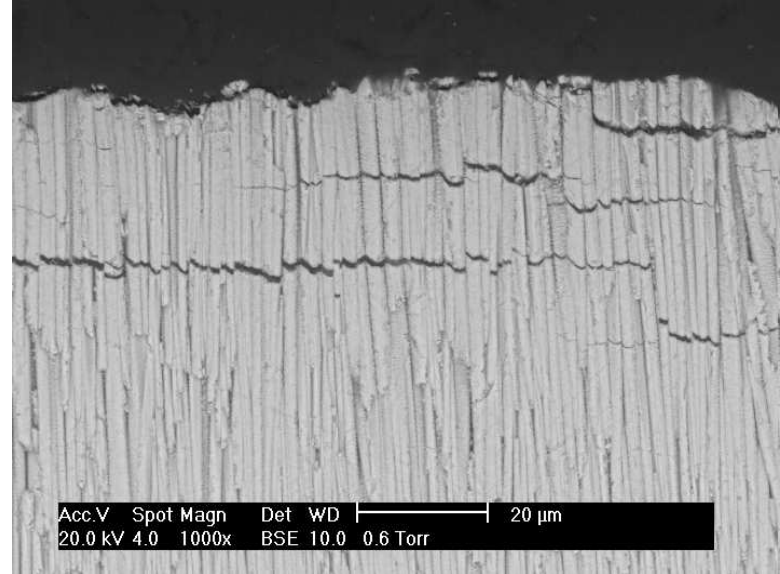

(a)

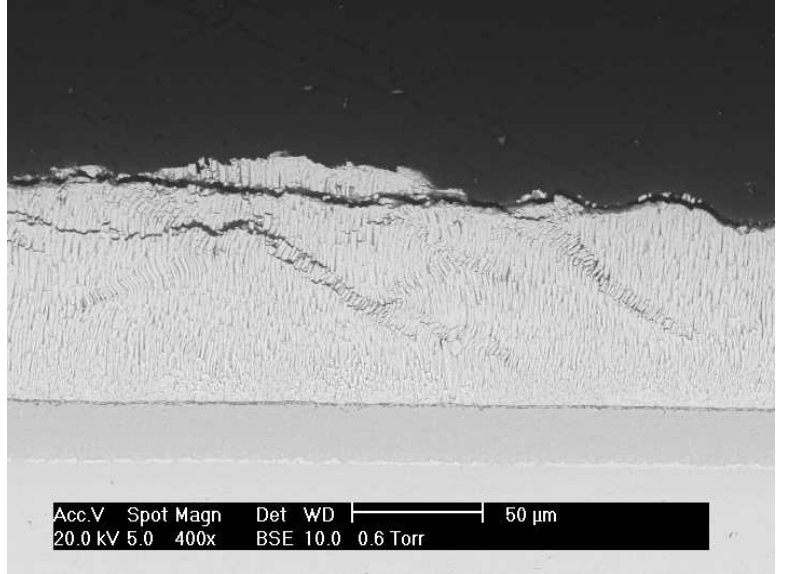

(b)

Figure 14: SEM micrograph showing erosion of a doped EBPVD TBC, a) at room temperature and b) at high temperature.

Recently Steenbakker et al [44] identified a new erosion mechanism while examining the effects of gadolinia additions on the erosion of EB PVD TBCs, where, due to the effect of the extremely narrow columns, 3-5 $\mu \mathrm{m}$ diameter, the coating behaved more as a continuum than as discreet columns. As can be seen in Figure 14a lateral cracks appear to propagate across the column boundaries without any difficulty. However, under the high temperature $\left(825^{\circ} \mathrm{C}\right)$ test conditions the erosion mechanism changed to a FOD mechanism, as illustrated in Figure 14b, with the associated cracking and kink bands. This change in mechanism was partly attributed to the increase in velocity of the $825^{\circ} \mathrm{C}$ tests over the room temperature tests and the associated increase in contact area, further illustrating the effect of the $\mathbf{D} / \mathbf{d}$ ratio on the erosion of EB PVD TBCs. During these tests the inlet gas pressure was maintained hence for the tests at high temperature, due to expansion, the gas outlet velocity was slightly higher than for the room temperature tests thus resulting in a higher particle impact velocity. Since a number of factors contribute to the contact footprint diameter including velocity, an increase in velocity results in an increase in contact diameter.

The dimensionless ratio $\mathbf{D} / \mathbf{d}$ has a number of advantages in determining the erosion regime for EB PVD TBCs and if coupled with strain rates during impact could be used to generate useful erosion maps. The column diameter of EB PVD TBCs is fairly standard for a given deposition process and can also be easily measured. While the contact footprint diameter includes a large number of important variables into one 
parameter, these variables include particle velocity, density, size and mechanical properties as well as the mechanical properties of the EB PVD TBC. The column diameters are easy to measure in cross section however, determining an accurate measure of the contact footprint diameter is slightly more difficult. In the case of compaction damage it is possible to measure the contact footprint by measuring impact sites in the SEM, in either the top view or cross section see Figure 9. This can also be done for FOD damage, however under erosion conditions this is very difficult to do. It is also possible to calculate the contact footprint for impact conditions this has been covered in a previous paper [20].

\subsection{OTHER FACTORS AFFECTING THE EROSION OF TBCS}

The first sections of this paper have covered the main erosion mechanisms of EB PVD TBCs and the relationship between the impact conditions and the erosion rates of EB PVD TBCs particularly the relationship between contact area and column diameter. This section will briefly consider other factors that have a significant effect on the erosion response of TBCs including aging, dopent addition and corrosion (CMAS attack).

\subsection{The Effect of Aging on the Erosion of PS and EB PVD TBCs}

For many years now the erosion rate of plasma sprayed TBCs has been quoted as being in the order of 10 times higher than their EB PVD equivalents as illustrated in Figure 3 of this paper. However, until recently nearly all erosion testing has been conducted on samples in the as sprayed/deposited condition, thus it was decided to determine the effects of aging on the erosion rates of both EB PVD and PS TBCs. In order to do this a number of samples were aged before erosion testing, initial testing showed that as the aging condition increases the erosion rate of EB PVD TBCs increases as illustrated in Figure 15[23].

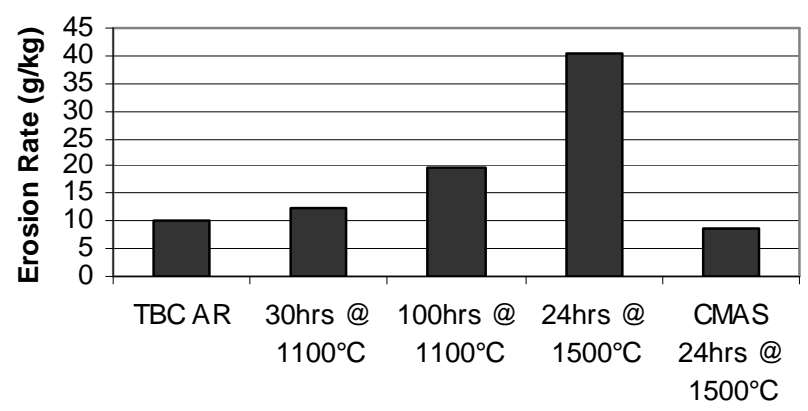

Figure 15: Effect of aging condition on the erosion of EB PVD TBCs at $90^{\circ}$ impact and room temperature, with data added showing the effect of CMAS on the erosion rate of EB PVD TBCs [23]. TBC AR - as received EB PVD TBC, CMAS - sample with CMAS infiltration.

This increase in the erosion rates has been attributed to the sintering of columns together, giving rise to larger 'columns', resulting in greater material removal per impact, when cracks are initiated in the coating. This is due to the fact that when the columns sinter together the sintered column boundaries no longer inhibit crack growth and cracks initiated during impact propagate further across the near surface region of the TBC resulting in greater material loss per impact[23]. In the as received condition the column boundaries all act as free surfaces and hence cracks initiated in one column do not propagate into the neighbouring columns. However, during sintering some of the columns will sinter together resulting in fewer larger columns within the coating; this sintering effect is illustrated in Figure 16. Note that not all the columns sinter, thus there are still free surfaces to stop crack propagation. The effect of the CMAS on the erosion rate is covered in section 4.3. 


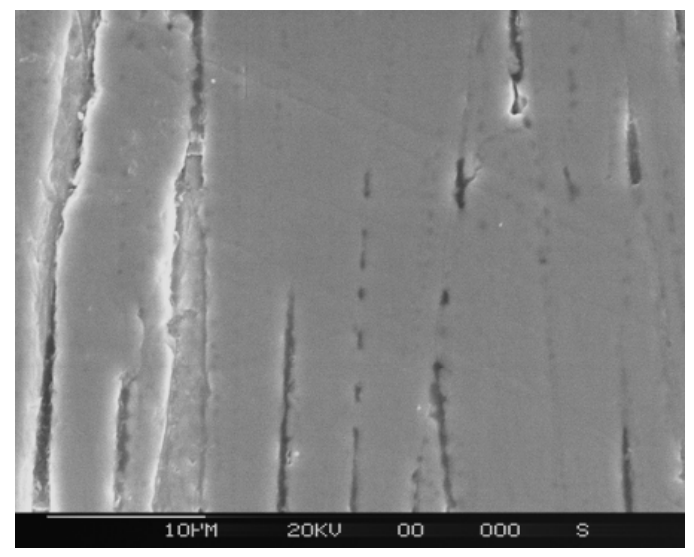

Figure 16: SEM micrograph of an EB PVD TBC showing sintering of the columns.

More recently the effects of aging on the erosion of PS TBCs (two different PS (from different suppliers) and one vertically cracked PS TBC) have been investigated with surprising results. As can be seen from the graph in Figure 17, aging the samples for $100 \mathrm{hrs}$ at $1100^{\circ} \mathrm{C}$ results in a decrease in erosion rate for PS TBCs. The sample labelled VC PS (vertically cracked plasma sprayed) has an erosion rate approaching that of an EB PVD TBC in the as received condition but after aging the erosion rates of the VC PS and the std EB PVD TBC are almost identical (within experimental error). The erosion tests reported in Figure 15 and 17 were all conducted under the same test conditions of room temperature and $90^{\circ}$ impact.

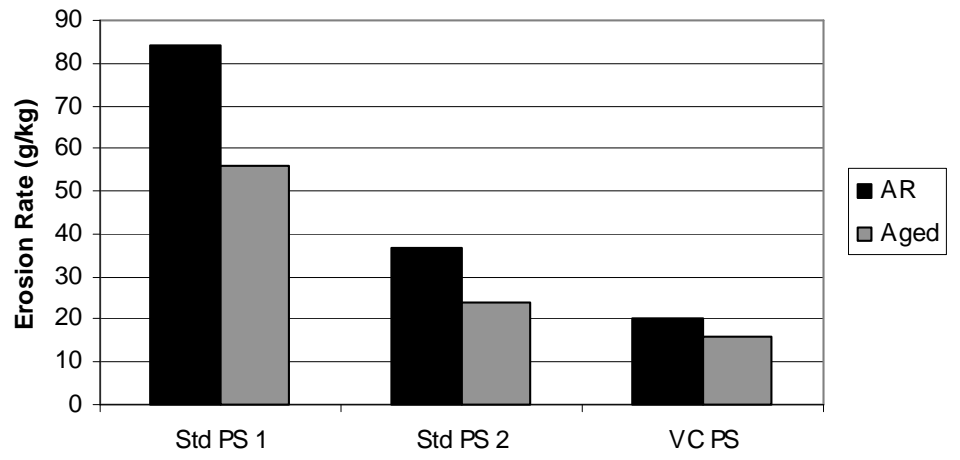

Figure 17: Effect of aging on the erosion of PS TBCs, at $90^{\circ}$ impact and room temperature [45] (std PS standard plasma sprayed sample as illustrated in Figure 1b, i.e. not vertical cracks).

This improvement in the erosion resistance of PS TBCs has been attributed to an increase in the intersplat bonding in the coating increasing the energy needed to initiate and propagate a crack along a splat boundary [45]. The erosion of PS TBCs has not been examined to the same degree as EB PVD TBCs, however, it is generally accepted that in PS TBCs erosion occurs via the initiation and propagation of cracks along the splat boundaries. This generally results in the loss of whole splats or groups of splats, thus any improvement in the adhesion between neighbouring splats will result in an increase in erosion resistance. This reduction in the erosion rate of the PS TBCs after aging is the opposite of what is observed for EB PVD TBCs. This increase in the erosion rate of EB PVD TBCs with aging (time in 
service) and decrease in the erosion rate of PS TBCs with aging greatly reduces the difference in the erosion rates between these two classes of TBCs.

\subsection{The Effect of Dopent Additions on the Erosion of EB PVD TBCs}

Additions of small quantities of rare earth oxides, for example gadolinia and dysprosia, have been shown to significantly reduce the thermal conductivity of EB PVD TBCs, thermal conductivities close to that of PS TBCs can be achieved with the addition of $2 \%$ gadolinia to a standard $7 \mathrm{wt} \%$ yttria partially stabilized zirconia EB PVD TBC [46].

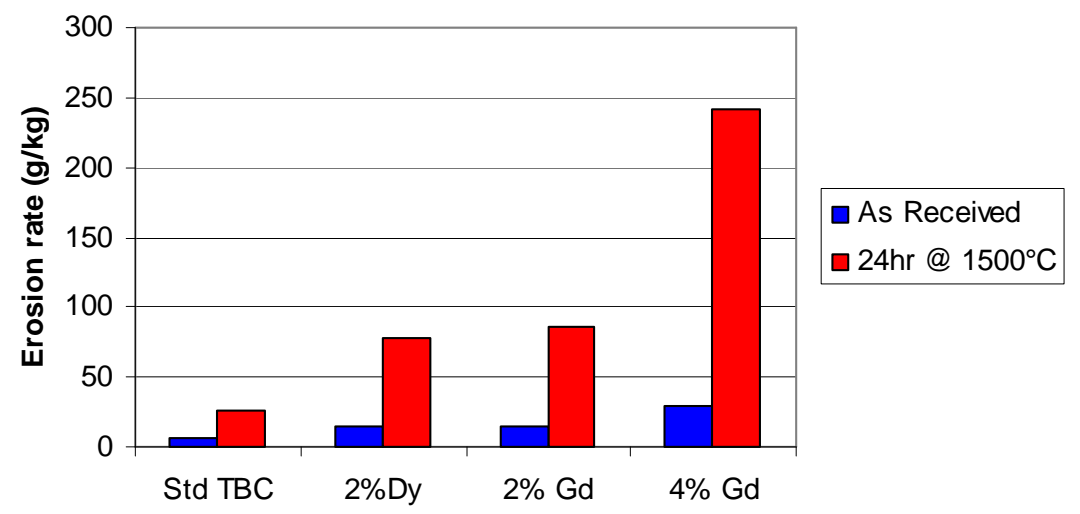

Figure 18: Effect of gadolinia and dysprosia additions on the erosion of EB PVD TBCs at room temperature.

However, as can be seen from the graph in Figure 18, the addition of dopents increases the erosion rate of EB PVD TBCs significantly; this increase is then further magnified when the samples are aged before erosion testing. In this graph: Std TBC - is an 7wt\% ytttria partially stabilized EB PVD TBC, $2 \%$ Dy - is a std EB PVD TBC doped with $2 \mathrm{~mol} \%$ dysprosia, $2 \% \mathrm{Gd}$ - is a std EB PVD TBC doped with $2 \mathrm{~mol} \%$ gadoliniaia, $4 \% \mathrm{Gd}$ - is a std EB PVD TBC doped with $4 \mathrm{~mol} \%$ gadoliniaia. This finding is similar to observations made by Steenbakker et al investigating the effects of gadolinia on the erosion of EB PVD $\mathrm{TBCs}$ at both room and high $\left(825^{\circ} \mathrm{C}\right)$ temperature [44].

\subsection{Corrosion of EB PVD TBCs (CMAS attack)}

Until recently the maximum surface temperatures of TBCs during peak operation conditions was lower than $1240^{\circ} \mathrm{C}$ and hence attack of the TBC by molten CMAS (calcium-magnesium-alumina-silicates) was not an issue. However, as the drive to more efficient engines continues and the reliability and performance of EB PVD TBCs improves, TBC surface temperatures of $1240^{\circ} \mathrm{C}$ and greater can occur during normal operating conditions. This is the temperature at which CMAS melts and, as it has excellent wetting properties, it can easily penetrate into the structure of the TBC. Since the TBC is in a thermal gradient the depth of penetration of the CMAS is limited to the point at which the TBC temperature is equal to the melting temperature of the CMAS. The SEM micrograph in Figure 19 shows how CMAS attack causes degradation of the TBC columnar microstructure, note that the dark regions in the micrograph are not porosity but in fact CMAS. This is accompanied by a metastable tetragonal $\left(\mathrm{t}^{\prime}\right)$ to monoclinic $(\mathrm{m})$ phase transformation with a significant degree of diffusion of $\mathrm{Y}$ and $\mathrm{Zr}$ into the infiltrating CMAS which fills the gaps between the TBC columns [47].

However, this chemical attack is not the only problem associated with CMAS damage of EB PVD TBCs, delamination of the regions infiltrated by the CMAS via a cold shock mechanism can cause significant 
and rapid loss of the TBC [24]. Upon cooling of the TBC to below $1240^{\circ} \mathrm{C}$ the CMAS will solidify and 'lock' the infiltrated columns together thus affecting the strain tolerance of the TBC. During shut down of the engine with its associated rapid cooling of the TBC high compressive stresses will develop in the surface region which can initiate cracking parallel to the surface of the TBC. Future engine cycles will result in the spallation of the TBC exposing 'fresh' TBC to CMAS attack.
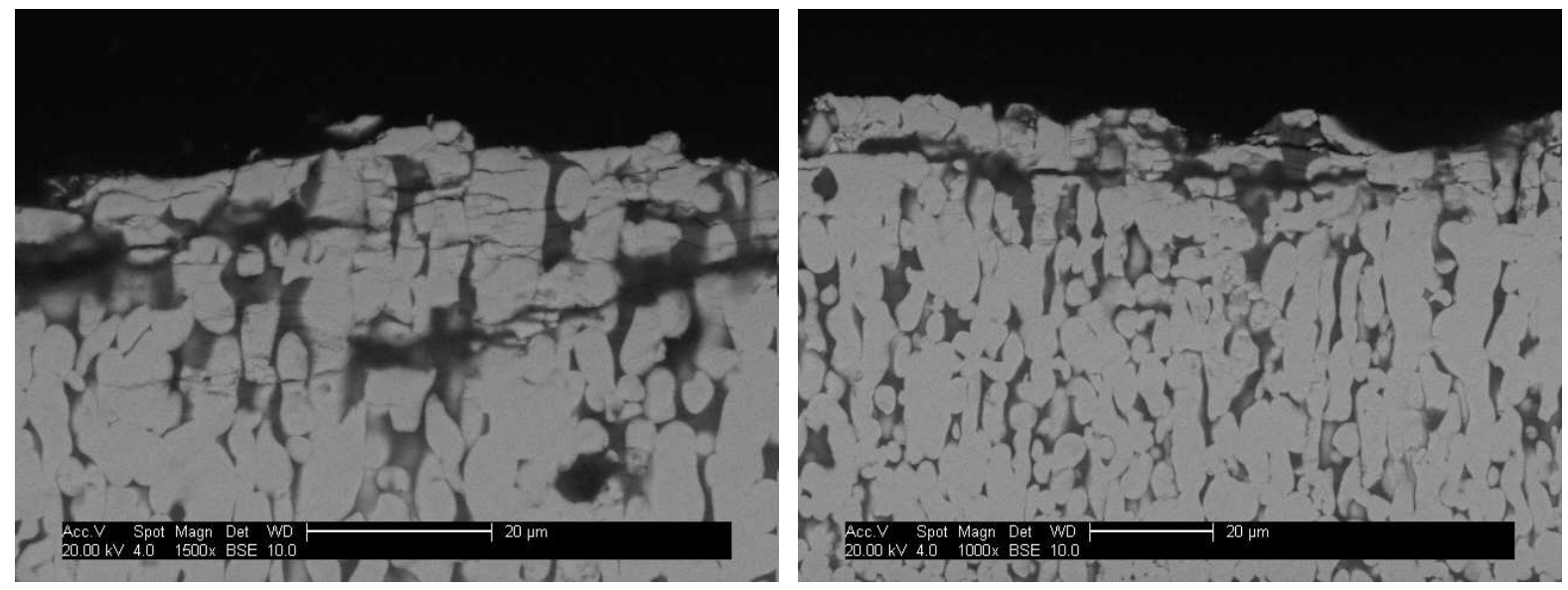

Figure 19: SEM micrographs of EB PVD TBCs that have been chemically attacked by CMAS prior to erosion testing, showing impact damage in the form of cracking.

During erosion of EB PVD TBCs, cracks, initiated by particle impact in the erosion regime, do not propagate across the column boundaries, resulting in a relatively low erosion rate, when compared to the erosion rate of aged samples or FOD. These cracked sections of the columns are then easily removed from the coating on subsequent impacts. The graph in Figure 15 shows that CMAS attack reduces the erosion rate compared to as received EB PVD TBCs. This reduction in the erosion rate is attributed to the fact that the coating is now acting as a continuum, i.e. like a bulk solid see results of bulk zirconia in Figure 3, with cracks propagating parallel to the surface and material only being removed when the propagating cracks intersect with the surface or each other. Due to the fact that there are no free surfaces, columns boundaries, the cracked regions of the CMAS infiltrated TBC are not easily removed.

The case illustrated above is for total CMAS penetration into the coating. However due to the fact that TBCs operate in a temperature gradient CMAS is not expected to penetrate significantly into a coating during normal operating conditions. If the penetration of the CMAS is only of the order of $20-30 \mu \mathrm{m}$ into the coating it is quite possible that "erosion-corrosion" type mechanisms will start to operate and that erosion rates will be highly dependent on depth of CMAS penetration relative to the contact area / depth of impact of the erodent particle. It is also possible that thin layers of CMAS could result in an increase in erosion rate, however more work needs to be done to ascertain the effects of partial penetration of CMAS on erosion rates.

\section{EROSION MODELS FOR EB PVD TBCS}

Recent work on TBC erosion has focused on understanding the material removal mechanisms for an EBPVD thermal barrier coating system under the wide range of impact conditions that may be envisaged in a gas turbine, as depicted in the micrographs in section 3 of this paper. These modeling studies have involved a collaboration between researchers at Cambridge [22,48], Santa Barbara [9,41,49] and Cranfield $[17,36,39,40,50]$, where Cranfield have provided much of the experimental evidence of the damage incurred. Cambridge has modeled the dynamics of particle impaction, examining in particular the 
evolution, propagation and dissipation of energy from the elastic stress wave during impaction. Work at Santa Barbara has focused on elasto-plastic interactions during large particle impact (FOD), by utilizing a high temperature indentation system to examine the flow characteristics of the TBC under indentation load. They have developed finite element (F.E.) models of the TBC system and compared the models to damage produced using depth sensing, spherical indentation, at temperature $[9,22,41,42]$. Figure 20 illustrates schematically these two modes of damage. Figure 20a is representative of coating failure during small particle erosion due to the propagation of elastic stress waves down the columns of an EBPVD TBC. Figure 20b illustrates the gross plastic damage and shear banding that results from foreign object damage (FOD).

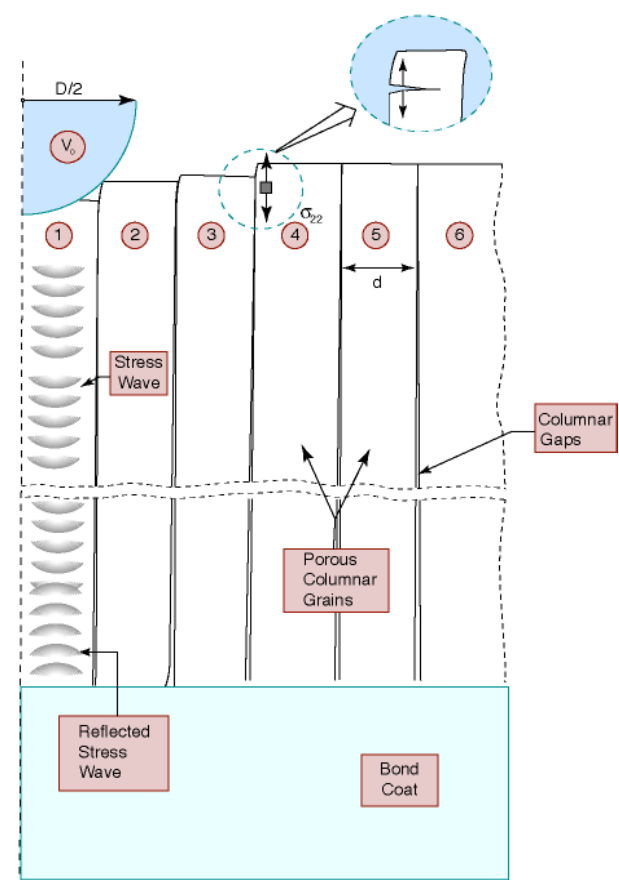

(a)

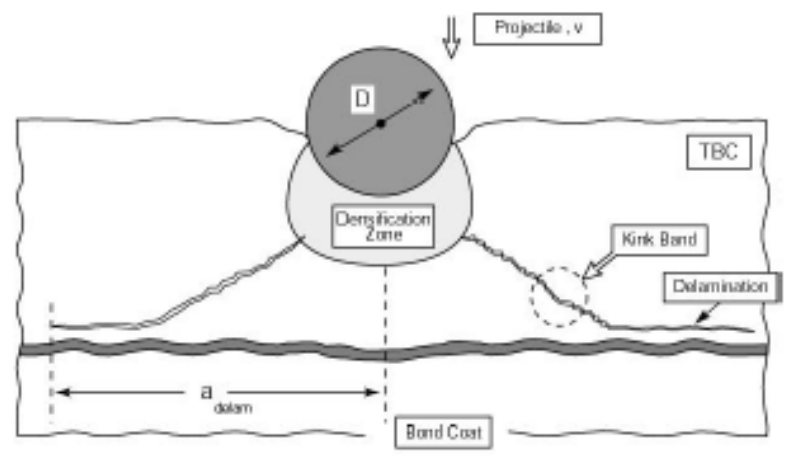

(b)

Figure 20: Schematic diagrams of particle impact dynamics on an EB-PVD TBC [22,48] a) elastic and b) plastic.

Modelling work at Cranfield [20,36,50] has focused on understanding the material removal mechanisms, and thus the development of a Monté Carlo model to predict EB PVD TBC erosion rates, whilst operating in the Mode I (small particle impact) damage regime. In support of this modeling work, and to provide indentation data (and mechanical properties) for individual columns and small clusters of columns, nanoand micro-indentation studies of the EB PVD columnar structure have been undertaken [43] complimenting the macro-indentation studies of Santa Barbara.

For completeness sake it is worth mentioning at this point that during the late 1980s and early 1990s Tabakoff [16] did a significant amount of work modeling particle trajectories through first stage turbines.

\section{CONCLUSIONS}

This paper has reviewed on-going research into the erosion and foreign object damage (FOD) to TBC systems looking at various factors that influence wastage rates. 
Experimental studies have shown that three primary damage regimes exist:-

Mode I : Small particle erosion, whereby damage is limited to the near surface region of the $\mathrm{TBC}$ and material removal results from cracking of neighbouring columns during impact, usually at a depth of $10-20 \mu \mathrm{m}$, and the conjoint loss of material from a cluster of adjacent columns. At high temperatures plastic deformation of the near surface region is observed and this defines the depth at which cracks propagate.

Mode II : Compaction damage occurs when gross plasticity/densification is observed as a result of the impact event, but the induced stresses/strains are insufficient to induce fracture within the TBC. In effect the impact energy density falls below some critical threshold. This mode has the effect of densifying the near surface of the coating, conditioning the TBC for later material removal due to small particle erosion or FOD.

Mode III : Foreign Object Damage (FOD). This is in effect a ballistic impact event. At its lower bound it may result in compaction damage, with possible lateral/shear crack development due to the large strains introduced during impaction. At its upper bound, extensive plasticity and densification occurs. Strain fields interact through the TBC and with the bondcoat and TGO. Under these conditions shear bands develop, propagating outward and down through the TBC, until they turn near the TGO interface to produce delamination cracks within the TBC ceramic, but parallel to the bondcoat/TGO/TBC interface. This is potentially the most damaging of the three mechanisms observed.

- The transition between damage modes depends on:- impact velocity, particle size, temperature and the relative size of the contact area to column diameter.

- D/d - Diameter Contact Area / Column Diameter is a critical experimental parameter that determines whether erosion/compaction/FOD occurs.

The effects of aging on the erosion rates are very different for EB PVD TBCs compared to PS TBCs:-

Aging of EB PVD TBCs results in a significant increase in the erosion rate due to the sintering of the columns. This becomes more pronounced as the time and or temperature of aging increases.

Aging of plasma sprayed TBCs results in a decrease in the erosion rate due to the sintering of the intersplat boundaries.

Dopent additions of gadolinia (2-4\%) and dysprosia (2\%) have been shown to significantly increase the erosion rate of EB PVD TBCs.

CMAS attack has been shown to degrade EB PVD TBC via a number of different mechanisms:

- $\quad$ Degrades the columnar microstructure.

- $\quad$ Facilitates the t' to monoclinic phase transformation.

- On cooling the system to below the CMAS melting point the TBC loses its strain tolerance and becomes susceptible to a cold shock delamination degradation mechanism.

However, when the CMAS penetrates a significant degree into the coating, the erosion rate is similar to that for an as received EB PVD TBC. This is because the CMAS degraded coating will act as a continuum rather than as discreet columns. 


\section{ACKNOWLEDGEMENTS}

The authors wish to acknowledge the many sponsors that have supported this work. Particularly Rolls Royce plc for support of the early experimental erosion studies, the UK MoD and most recently the European Commission, through the joint NSF/EU HIPERCOAT programme contract no GRD2-20030211. Some sections of this paper have been presented at the RTO AVT Specialists' Meeting on "The Control and Reduction of Wear in Military Platforms" held in Williamsburg, USA 7-9 June 2003 and at the TRIBOCORROSION 2006 Symposium held in Hyderabad, India 5-6 Dec 2006.

\section{REFERENCES}

1. W.J Moore, Physical Chemistry, Longmans, London, 1972.

2. S Bose and J Demasi-Marcin, Thermal Barrier Coatings Workshop NASA Conference Publication 3312 (1995) 63.

3. R.A Miller, Thermal Barrier Coatings Workshop NASA Conference Publication 3312 (1995) 17.

4. J.R Nicholls, K.J Lawson, D.S Rickerby and P Morrell, Thermal Barrier Coatings, Agard Report $\underline{823}$, (1998) Paper 6.

5. $\quad$ D. Zhu and R. A. Miller, Ceram. Eng. Sci Proc, 23, (2002) 457.

6. J.R Nicholls, K.J Lawson, A Johnson and D.S Rickerby, Surface and Coatings Technology, 151152 , (2002) 383.

7. M. J. Maloney, Thermal Barrier Coating Systems and Materials, US Patent 6177200 Hartford (CT,USA) (2001).

8. D. Zhu, J. A. Nesbitt, T. R. McCue, C. A. Barrett and R. A. Miller, Ceram. Eng. Sci. Proc, 23, (2002) 533.

9. M. Watanabe, C. Mercer, C. G. Levi and A. G. Evans, Acta Materialia, 52, (2004) 1479.

10. T.A Cruse, S.E Stewart and M Ortiz, Transactions of the ASME, 110, (1988) 610.

11. B.C Wu, E Chang, S.F Chang and C.H Chao, Thin Solid Films, 172, (1989) 185.

12. J.H Sun, E Chang, B.C Wu and C.H Tsai, Surface and Coatings Technology, 58, (1993) 93.

13. D.M Nissley, Thermal Barrier Coatings Workshop NASA Conference Publication 3312 (1995) 265.

14. F.C Toriz, A.B Thakker and S.K Gupta, Surface and Coatings Technology, 39/40, (1989) 161.

15. P Morrel and D.S Rickerby, AGARD Report 823 (1998) 20.

16. W Tabakoff, Surface and Coatings Technology, 30/40, (1989) 97.

17. J.R Nicholls, Y Jaslier and D.S Rickerby, Materials at High Temperature, 15, (1998) 15.

18. A.G Davis, D.H Boone and A.V Levy, Wear, 110, (1986) 101.

19. T Rhys-Jones and F.C Toriz, High Temperature Technology, $\underline{7}$, (1989) 73.

20. R.G Wellman and J.R Nicholls, Wear, 242, (2000) 89.

21. R.G Wellman, M.J Deakin and J.R Nicholls, Wear, 258, (2005) 349.

22. X Chen, M.Y He, I Spitsberg, N.A Fleck, J.W Hutchinson and A.G Evans, Wear, 256, (2004) 735.

23. R.G Wellman and J.R Nicholls, Surface and Coatings Technology, 177-178, (2004) 80.

24. C Mercer, S Faulhaber, A.G Evans and R Darolia, Acta Materialia, $\underline{53}$, (2005) 1029.

25. S. M. Meier and D. K. Gupta, Journal of Engineering for Gas Turbine and Power, 116, (1994) 250.

26. D. S. Rickerby and P. Morrell, AGARD-R0823 (1998) paper 20.

27. S. Alperine, M. Derrien, Y. Jaslier and R. Mevrel, AGARD-R-833 (1998) Paper 1.

28. R. A. Miller, NASA TM4087, 1998.

29. S. M. Meier, Journal of Engineering for Gas Turbines and Power, 114, (1992).

30. W.A Nelson and R.M Orenstein, J. of Thermal Spray Technology, $\underline{6}$, (1997) 176.

31. J.R Nicholls, M.J Deakin and D.S Rickerby, Wear, 233-235, (1999) 352. 
32. J. R. Nicholls, Mater. at High Temp, 14, (1997) 289.

33. R.A Miller, Surface and Coatings Technology, 30, (1987) 1.

34. M. R. Dorfman and J. D. Reardon, NASA TBC Workshop (1985).

35. J.R Nicholls, Y Jaslier and D.S Rickerby, Mater. Sci. Forum, 251-254, (1997) 935.

36. R.G Wellman and J.R Nicholls, Mater. Sci. Forum, 369-372, (2001) 531.

37. R. G. Wellman and J. R. Nicholls, Wear, 256, (2004) 889.

38. H.E Eaton and R.C Novak, Surface and Coatings Technology, 30, (1987) 41.

39. J. R. Nicholls, R. G. Wellman and M. J. Deakin, Materials at High Temperatures, 20, (2003) 207.

40. R.G Wellman and J.R Nicholls, Workshop on Thermal Barrier Coatings , 2003.

41. X Chen, J.W Hutchinson and A.G Evans, Acta. Materialia, 52, (2004) 565.

42. X Chen, R Wang, N Yao, A.G Evans, J.W Hutchinson and R.W Bruce, Materials Science and Engineering A, in Press, (2002).

43. R.G Wellman, A Dyer and J.R Nicholls, Surface and Coatings Technology, 176, (2004) 253.

44. R.J.L Steenbakker, R.G Wellman and J.R Nicholls, Surf. Coat. Technol., 201, (2006) 2140.

45. R.G Wellman, E Besnard, T.W Clyne and J.R Nicholls, Euromat 2005, 2005.

46. J.R Nicholls , K.J Lawson, A Johnson and D.S Rickerby, Surface and Coatings Technology, 151$\underline{152}$, (2002) 383.

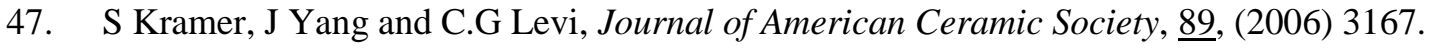

48. N.A Fleck, Thermal Barrier Coating Workshop, 2004.

49. X Chen, M.Y He, I Spitsberg, N.A Fleck, J.W Hutchinson and A.G Evans, Wear (2003).

50. R.G Wellman and J.R Nicholls, Wear, 256, (2004) 889. 